\author{
Anna Bryland \\ Marcus Broman \\ Martin Erixon \\ Bengt Klarin \\ Torbjörn Lindén \\ Hans Friberg \\ Anders Wieslander \\ Per Kjellstrand \\ Claudio Ronco \\ Ola Carlsson \\ Gabriela Godaly
}

\title{
Infusion fluids contain harmful glucose degradation products
}

Received: 26 June 2009

Accepted: 7 March 2010

Published online: 16 April 2010

(C) The Author(s) 2010. This article is published with open access at Springerlink.com

A. Bryland and M. Broman contributed equally to this work.

Electronic supplementary material

The online version of this article (doi:10.1007/s00134-010-1873-x) contains supplementary material, which is available to authorized users.

\author{
A. Bryland \\ Department of Nephrology, \\ Lund University, Lund, Sweden \\ M. Broman - B. Klarin · H. Friberg \\ Department of Anaesthesiology and \\ Intensive Care, \\ Lund University Hospital, Lund, Sweden

\section{Erixon} \\ Department of Analytical Chemistry, \\ Lund University, Lund, Sweden \\ T. Lindén · A. Wieslander · \\ P. Kjellstrand · O. Carlsson \\ Gambro Lundia AB, Lund, Sweden \\ C. Ronco \\ Department of Nephrology, \\ St. Bortolo Hospital, Vicenza, Italy
}

G. Godaly ( )

Department of Microbiology,

Immunology and Glycobiology,

Lund University, Lund, Sweden

e-mail: gabriela.godaly@med.lu.se

Tel.: +46-46-173233

Fax: +46-46-137468

Abstract Purpose: Glucose degradation products (GDPs) are precursors of advanced glycation end products (AGEs) that cause cellular damage and inflammation. We examined the content of GDPs in commercially available glucose-containing infusion fluids and investigated whether GDPs are found in patients' blood. Methods: The content of GDPs was examined in infusion fluids by high-performance liquid chromatography (HPLC) analysis. To investigate whether GDPs also are found in patients, we included 11 patients who received glucose fluids (standard group) during and after their surgery and 11 control patients receiving buffered saline (control group). Blood samples were analyzed for GDP content and carboxymethyllysine (CML), as a measure of AGE formation. The influence of heat-sterilized fluids on cell viability and cell function upon infection was investigated. Results: All investigated fluids contained high concentrations of GDPs, such as 3-deoxyglucosone (3-DG). Serum concentration of 3-DG increased rapidly by a factor of eight in patients receiving standard therapy. Serum CML levels increased significantly and showed linear correlation with the amount of infused 3-DG. There was no increase in serum 3-DG or CML concentrations in the control group. The concentration of GDPs in most of the tested fluids damaged neutrophils, reducing their cytokine secretion, and inhibited microbial killing. Conclusions: These findings indicate that normal standard fluid therapy involves unwanted infusion of GDPs. Reduction of the content of GDPs in commonly used infusion fluids may improve cell function, and possibly also organ function, in intensive-care patients.

Keywords Glucose - Infusion fluids . Toxicity - Advanced glycation end products · Neutrophils - Innate defense $\cdot$ Cell survival

\section{Introduction}

Isotonic glucose solutions are frequently used in intensive care units (ICUs) to hydrate patients with acute disease or after surgery. These commercially available fluids contain between $2.5 \%$ and $50 \%$ glucose and are heat-sterilized to assure sterility of the products. Beyond hydration, these sterile products provide calories. Dysregulated glucose 
homeostasis occurs frequently in critically ill patients, but strict glycemic control does not decrease infectious morbidity, mortality, and length of stay in the ICU [1-4]. Glucose is seen as an inexpensive and secure source of energy on the one hand, and as a harmful substance on the other. What is perhaps less known is that the sterilization process of these fluid products leads to degradation of the glucose to highly bioreactive glucose degradation products (GDPs).

Glucose is used as an osmotic agent in fluids for peritoneal dialysis (PD) to remove water from patients with renal failure. Heat-sterilization of glucose-containing PD fluids promotes formation of a large number of GDPs [5]. Several GDPs, such as 3-deoxyglucosone (3-DG), 3,4-dideoxyglucosone-3-ene (3,4-DGE), 5-hydroxymethyl-2-furaldehyde (5-HMF), and formaldehyde, have been identified in PD fluids [6, 7]. At the cellular level, aldehydes disrupt cell signaling and cause extensive damage to membrane lipids, cellular proteins, mitochondrial function, RNA, and DNA [8]. The most bioreactive GDP in heat-sterilized PD solutions is 3,4-DGE [7]. This toxic molecule was found to impair wound healing and to induce apoptosis in human leukocytes and renal epithelial cells [9-11]. Highly reactive GDPs, such as 3,4-DGE, react instantly with different molecules, while others, such as 3-DG and 5-HMF, remain in circulation [12].

After reaching the blood, GDPs bind to serum proteins, which gives rise to advanced glycation end products (AGE) [13]. AGEs are known to be involved in oxidative stress and are associated with cardiovascular morbidity and renal injury [14-16]. By using new manufacturing techniques, PD solutions with low GDP content have been produced [17, 18]. Such low-GDP PD solutions have been shown to reduce serum AGE levels [13, 19] and decrease serum 3-DG concentrations [20]. Several other clinical studies have demonstrated that removal of GDPs from fluids leads to decreased inflammation, preserved kidney function, and improved patient outcomes [19, 21-23].

In order to evaluate whether isotonic glucose-containing infusion fluids include toxic GDPs, we examined the content of such substances in commercially available glucose solutions and the effect they exhibited on neutrophil function. Furthermore, we analyzed patients' blood for GDPs and CML after receiving standard glucose-containing fluid therapy in the postoperative setting and compared the serum levels with those of patients receiving buffered saline.

\section{Methods}

Fluids

Seven different brands of glucose-containing infusion fluids, which are routinely used in the ICU setting at Lund University Hospital (Lund, Sweden), were investigated (Table 1).

\section{Patients}

The study was approved by the Regional Ethical Review Board (DNR 207/2007) of Lund University, Sweden. After patients gave written informed consent to be included in the study, 11 patients (6 women and 5 men) receiving glucose-containing postoperative infusion fluids were included in the standard group, and 11 patients $(6$ women and 5 men) receiving buffered saline (Ringer's acetate) were included in the control group. Serum was analyzed for GDPs and CML.

Studies of effects of GDPs on cell viability and cell function

Cell viability was determined on isolated human neutrophils using the Thiazolyl blue tetrazolium bromide (MTT) assay. As an experimental infection model, neutrophils were infected with $E$. coli in the presence of GDPs or

Table 1 Content of GDPs in the investigated infusion fluids

\begin{tabular}{|c|c|c|c|c|c|c|c|}
\hline \multirow[t]{2}{*}{ Number } & \multirow[t]{2}{*}{ Name } & \multirow[t]{2}{*}{ Company } & \multirow[t]{2}{*}{ Glucose $(\%)$} & \multicolumn{4}{|c|}{ GDP concentrations $(\mu \mathrm{M})^{\mathrm{b}}($ mean \pm SEM) } \\
\hline & & & & 3-DG & 3,4-DGE & 5-HMF & Formaldehyde \\
\hline 1 & Glucos Fresenius 200 & Fresenius Kabi AB & 20 & $583 \pm 9.7$ & $59 \pm 1.2$ & $105 \pm 7.7$ & $19 \pm 3.4$ \\
\hline 2 & Glucos Fresenius 300 & Fresenius Kabi AB & 30 & $790 \pm 21.7$ & $56 \pm 2.3$ & $146 \pm 7.1$ & $34 \pm 4.7$ \\
\hline 3 & Rehydrex & Fresenius Kabi AB & 2.5 & $141 \pm 0.7$ & $22 \pm 1.1$ & $2 \pm 0.2$ & $17 \pm 0.7$ \\
\hline 4 & Glucos Baxter & Baxter Medical AB & 10 & $400 \pm 9.7$ & $50 \pm 0.1$ & $42 \pm 1.6$ & $10 \pm 3.0$ \\
\hline 5 & Glucos Baxter 25/50 & Baxter Medical AB & 2.5 & $123 \pm 0.8$ & $22 \pm 0.2$ & $2 \pm 0.1$ & $10 \pm 1.1$ \\
\hline 6 & Glucos BaxterViaflo & Baxter Medical AB & 5 & $238 \pm 3.9$ & $35 \pm 0.6$ & $17 \pm 0.4$ & $4 \pm 1.2$ \\
\hline & Glucos Baxter Na40 K20 & Baxter Medical AB & 10 & $358 \pm 5.4$ & $59 \pm 0.4$ & $10 \pm 0.3$ & $21 \pm 2.8$ \\
\hline $\mathrm{LC}^{2} 0^{\mathrm{a}}$ & & & & $1,374 \pm 47.9$ & $47 \pm 2.7$ & $2,463 \pm 64.2$ & $44 \pm 5.1$ \\
\hline
\end{tabular}

\footnotetext{
${ }^{\text {a }}$ LC50 is the concentration $(\mu \mathrm{M})$ of GDPs that kills $50 \%$ of neutrophils

b Each value represents the mean \pm standard error of the mean $(\mathrm{SEM})(n=3)$
} 
with infusion fluids 2 and 3 or their respective sterile filtered control fluids. Secretion of CXCL8 and interleukin 6 (IL-6) by the infected neutrophils was quantified in supernatants by enzyme-linked immunosorbent assay (ELISA, RD Systems Europe). Capacity of neutrophil microbial killing was measured by Fc-OxyBURST (Invitrogen) according to the manufacturer's instructions.

Detailed methods are described in the Electronic Supplementary Material.

\section{Results}

GDPs found in all investigated infusion fluids

In all of the tested fluids, 3-DG, 3,4-DGE, 5-HMF, and formaldehyde were found (Table 1). The concentration of 3DG varied from 123 to $790 \mu \mathrm{M}$, of 3,4-DGE from 22 to $59 \mu \mathrm{M}$, of 5 -HMF from 2 to $146 \mu \mathrm{M}$, and of formaldehyde from 4 to $34 \mu \mathrm{M}$ (Table 1). The concentration of methylglyoxal was between 7 and $17 \mu \mathrm{M}$ in fluids 3 and 5-7, but below the detection limit $(1.0 \mu \mathrm{M})$ for the rest of the fluids. Acetaldehyde was only found in fluids 3,5 , and 7 , at very low concentrations $(1-2 \mu \mathrm{M})$ and close to the limit of detection $(<1.1 \mu \mathrm{M})$. Glyoxal concentration was below the detection limit $(3.4 \mu \mathrm{M})$ in most of the fluids, except fluid 3 that contained $31 \mu \mathrm{M}$. The concentrations of acetaldehyde, methylglyoxal, and glyoxal were far lower than the LC50 values [7, 24]. The concentrations of GDPs in sterile filtered control fluids were below the limit of detection.

\section{GDPs in blood circulation}

To ascertain whether the GDPs in glucose-containing infusion fluids could be found in patient blood circulation, we investigated patients who received glucose-containing fluids $(2.5 \%$ or $5 \%$; numbers 5 and 6 in Table 1$)$ within their normal treatment (standard group) and compared them with the control group who did not receive the glucose-containing fluids (Fig. 1). Levels of 3-DG, 3,4-DGE, formaldehyde, and 5-HMF were measured in serum samples before infusion and after $0.5,3,6$, and $9 \mathrm{~h}$.

Before infusion the serum from all patients in the standard group and in the control group contained normal amounts of 3-DG (approximately $0.2 \mu \mathrm{M}$; Fig. 1; Table 2). The amount of serum 3-DG in the standard group increased immediately after infusion and declined slowly thereafter, but had not reached the background level after $9 \mathrm{~h}$. There were some differences in individual serum levels of 3-DG that could not be correlated to the amount of infusions, clearance or the glucose content of the infused solutions. There was no increase in the amount of serum 3-DG in the control group. In addition, we found a significant difference between the groups during the infusion $(P \leq 0.001)$ and at

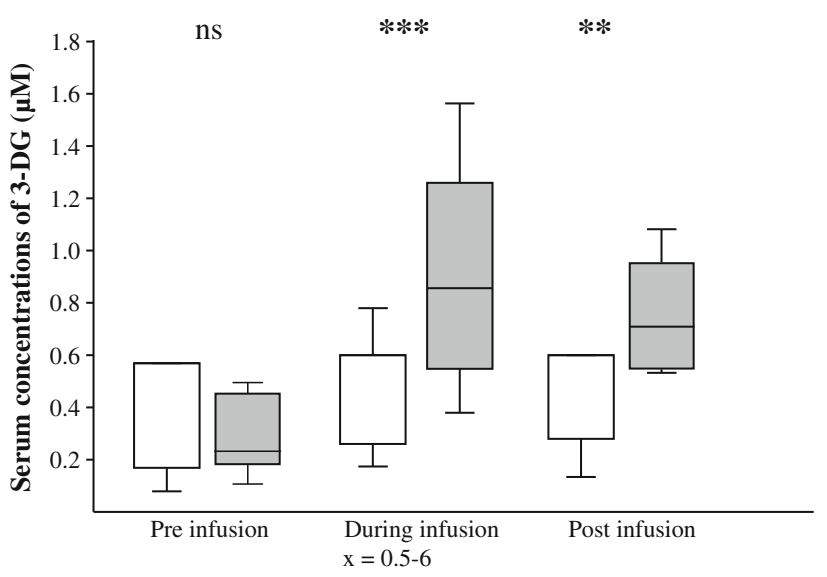

Fig. 1 GDPs found in patient serum. Concentration of 3-DG $(\mu \mathrm{M})$ in serum of patients receiving glucose-containing infusion fluids and the control group: before infusion $(0 \mathrm{~h})$, mean values during infusion $(0.5-6 \mathrm{~h})$, and at the end of infusion $(9 \mathrm{~h})$. The amount of serum 3-DG increased rapidly after infusion of glucose-containing infusion fluids and did not reach the background level even after $9 \mathrm{~h}$. The control group showed significantly less variability of serum 3-DG concentrations throughout the study. The statistical difference between the groups was calculated with Mann-Whitney/ Student $t$ test ( $n s$ nonsignificant, $* * P<0.01, * * * P \leq 0.001$ )

Table 2 Serum concentrations $(\mu \mathrm{M})$ of 3-DG in patients receiving the glucose-containing infusion fluids

\begin{tabular}{lllllc}
\hline Time $(\mathrm{h})$ & 0 & 0.5 & 3 & 6 & 9 \\
\hline Mean & 0.19 & 1.54 & 0.48 & 0.50 & 0.50 \\
SEM & 0.02 & 0.19 & 0.10 & 0.09 & 0.08 \\
$P$ & & $<0.001$ & 0.002 & 0.006 & $<0.001$
\end{tabular}

Significance values were evaluated by one-way analysis of variance, Dunn comparisons test, and Mann-Whitney/Student $t$ test

the end of the infusion $(P=0.004)$. The amount of 5-HMF in the standard group was at a normal concentration of $0.87 \mu \mathrm{M}$ at the start of the study [25], increased steadily after infusion, and reached a maximum after $9 \mathrm{~h}(1.75 \mu \mathrm{M})$. The serum concentration of 5-HMF was doubled at the end of the study, but we could not find any statistical difference between the groups. The amount of 5-HMF in the control patients was below the limit of detection $(1.0 \mu \mathrm{M})$ throughout the study. None of the more reactive GDPs, 3,4DGE and formaldehyde, could be detected in the serum from any patients.

\section{Urinary GDP levels}

Patients' urine was collected throughout the study for analysis of GDPs. Urine concentrations were then compared with the amount of 3,4-DGE, 3-DG, and 5-HMF that the patient group received during their therapy (see Supplementary Fig. 1). An average patient in the standard 
group received approximately 1.71 infusion fluids, which contained $47 \mathrm{mg}$ 3-DG, $7 \mathrm{mg}$ 3,4-DGE, $2 \mathrm{mg}$ 5-HMF, and $0.4 \mathrm{mg}$ formaldehyde. A tenth of the infused 3-DG was found in the urine $(4.5 \mathrm{mg}, P=0.0002)$, while the amount of 5-HMF was four times higher $(8.7 \mathrm{mg}$, $P=0.0314)$ than the infused amount. We found no 5 -HMF in the control group and on average $0.1 \mathrm{mg} 3$-DG $(P \leq 0.001$ compared with the patient group, data not shown). No 3,4-DGE or formaldehyde was found in urine.

\section{AGE formation}

We found a linear correlation between the infused 3-DG and the increased CML formation (see Supplementary Fig. 2) in the standard group. Nine hours after receiving the initial treatment with infusion fluids, the patients showed a significant increase of CML in serum (Fig. 2). There was no increase in serum CML formation in the control group $(P \leq 0.001)$.

\section{Heat-sterilized infusion fluids reduce cell viability}

The difference between infusion fluids and control fluids is shown in Fig. 3. All fluids were diluted to physiological levels, as regards osmolarity and glucose, before they were incubated with neutrophils (Fig. 3). The table illustrates the content of GDPs in the diluted fluids. Even though the fluids were substantially diluted, we found that all but one of the investigated infusion fluids significantly

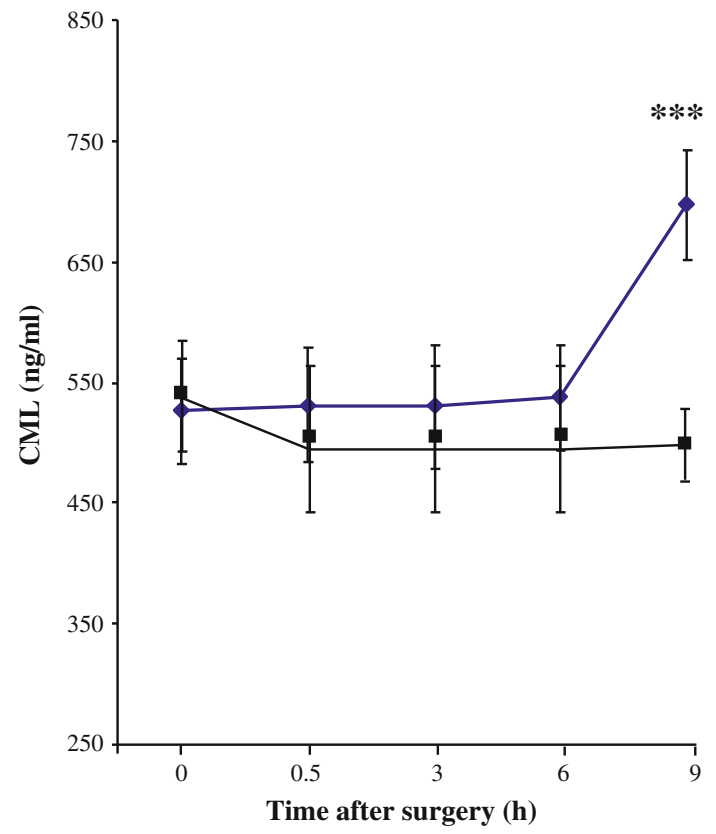

Fig. 2 Serum CML concentrations. Time dependency of the CML serum concentrations in patients after receiving the infusion fluids and in the control group. Data are shown as mean $\pm S E M$; $* P<0.05, * * P<0.01, * * * P \leq 0.001$ decreased cell viability compared with control fluids. Fluid 2, which originally contained the highest glucose concentration and hence was diluted most (1:15), was the one that was least harmful to neutrophils.

Dose response and lethal concentrations

To investigate the influence of GDPs on human cells, neutrophils were incubated with different concentrations of 3,4-DGE, 3-DG, and 5-HMF. The lethal concentration of GDPs that killed 50\% of neutrophils (LC50) was compared with the concentration of GDPs found in the infusion fluids (Table 1). The LC50 value for the most reactive GDPs, 3,4DGE and formaldehyde, was 47 and $44 \mu \mathrm{M}$, respectively. The majority of the investigated fluids contained higher concentrations of 3,4-DGE than $47 \mu \mathrm{M}$ (Table 1). The LC50 value for the less reactive molecules 3-DG and 5$\mathrm{HMF}$ was higher, $1,374 \mu \mathrm{M}$ and $2,463 \mu \mathrm{M}$, respectively.

GDPs diminished the inflammatory response

The possible immunomodulatory role of GDPs was investigated by measuring CXCL8 and IL-6 secretion upon

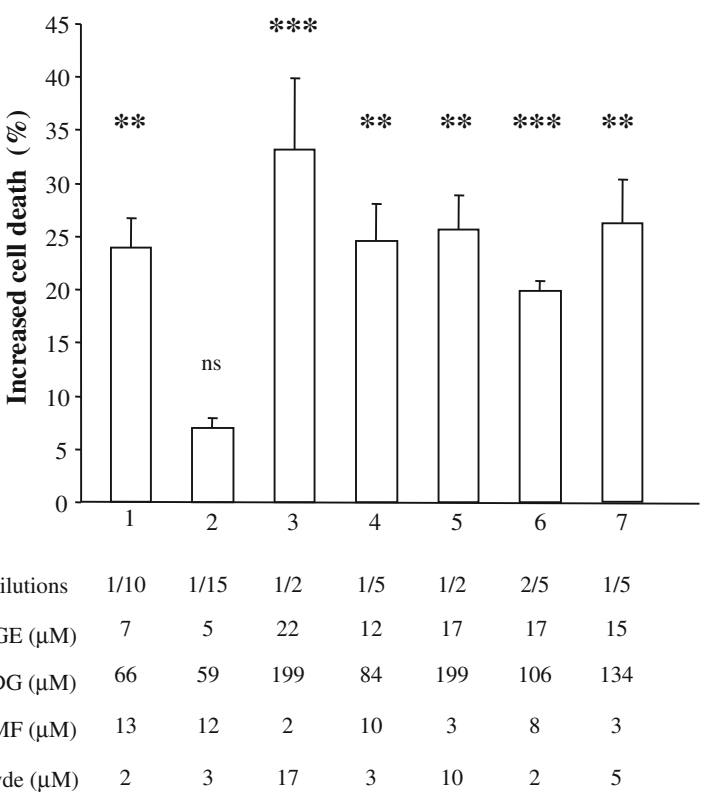

Fig. 3 Heat-sterilized infusion fluids reduce cell viability. Commercial heat-sterilized infusion fluids were compared with the control fluids. The figure shows the difference in cell survival between neutrophils treated with infusion fluids or with sterile filtered control fluids after $4 \mathrm{~h}$ of incubation. Mean of seven separate experiments $( \pm$ SEM $)$. The fluids were diluted to achieve physiological concentrations of glucose $(2 \%)$ and osmolarity $(285 \mathrm{mOsm} / \mathrm{l})$. Concentrations of the GDPs in the diluted fluids are presented in the table in the figure. Statistical difference between heat-sterilized infusion fluids and control fluids was calculated with Mann-Whitney test/Student $t$ test $(* P<0.05$, $* * P<0.01, * * * P<0.001, n s$ nonsignificant) 
bacterial infection. E. coli infection of human neutrophils induced secretion of both inflammatory cytokines (see Supplementary Figs. 3 and 4). Normal background cytokine production in uninfected neutrophils was $99 \pm 4 \mathrm{pg} / \mathrm{ml}$ for CXCL8 and $63 \pm 20 \mathrm{pg} / \mathrm{ml}$ for IL-6. The background production was set at zero in Supplementary Figs. 3 and 4. The presence of GDPs, at the same concentration that was found in an average infusion fluid, clearly suppressed secretion of both CXCL8 and IL-6. CXCL8 secretion was reduced by $57 \%$ with formaldehyde, $43 \%$ with 3,4-DGE, 33\% with 3-DG, and 30\% with 5-HMF. CXCL8 secretion was also inhibited with the physiologically diluted fluids 2 and $3(10 \%$ and $38 \%$, respectively) (see Supplementary Fig. 3), suggesting a correlation with their content of GDPs. Neutrophil IL-6 secretion upon infection was suppressed in the presence of formaldehyde, 3,4-DGE, and 3-DG $(98 \%, 72 \%$, and 59\%, respectively) compared with the positive control (Fig. 4). A smaller inhibitory effect (28\%) was found with 5-HMF. The diluted fluid 3, with the highest content of GDPs, suppressed IL-6 secretion by $73 \%$, while the more diluted fluid 2 was less inhibitory (10\%). The sterile filtered control fluids were not found to inhibit neutrophil cytokine secretion.

To investigate the impact of GDPs on neutrophil function, we measured the nicotinamide adenine dinucleotide phosphate (NADPH) oxidase-mediated secretion of reactive oxygen species (ROS) from infected cells (see Supplementary Fig. 4). Formaldehyde and 3,4-DGE significantly inhibited neutrophil microbial killing, by $43 \%$ and $56 \%$, respectively $(P<0.001)$, while 3 -DG and 5 -HMF suppressed neutrophil microbial killing by $35 \%$ and $23 \%(P<0.01)$. Neutrophil capacity to kill bacteria was further inhibited with fluid $3(57 \%)$ and to a lesser extent with fluid $2(10 \%)$. The sterile filtered control fluids were not found to reduce neutrophil ROS secretion.

\section{Discussion}

All investigated glucose-containing infusion fluids contained high amounts of GDPs. Moreover, increased concentrations of GDPs were found in blood circulation of critically ill patients receiving standard postoperative fluid therapy. The amount of 3-DG in the serum of a healthy human is approximately $0.2 \mu \mathrm{M}$ [26], and increases twofold with disease such as diabetes and threefold in uremia [26]. Before infusion, all patients had normal levels of 3-DG, but the concentration increased eightfold shortly after infusion of glucose-containing infusion fluids and did not reach the background level even after $9 \mathrm{~h}$. In contrast, serum and urinary 3-DG levels were low in the control patients who received buffered saline. This finding suggests that the increased 3-DG found in serum of patients receiving the standard postoperative fluid therapy with glucose originated from the high amounts of GDPs found in these fluids. We did not succeed in measuring the amount of the more reactive GDPs, since these molecules

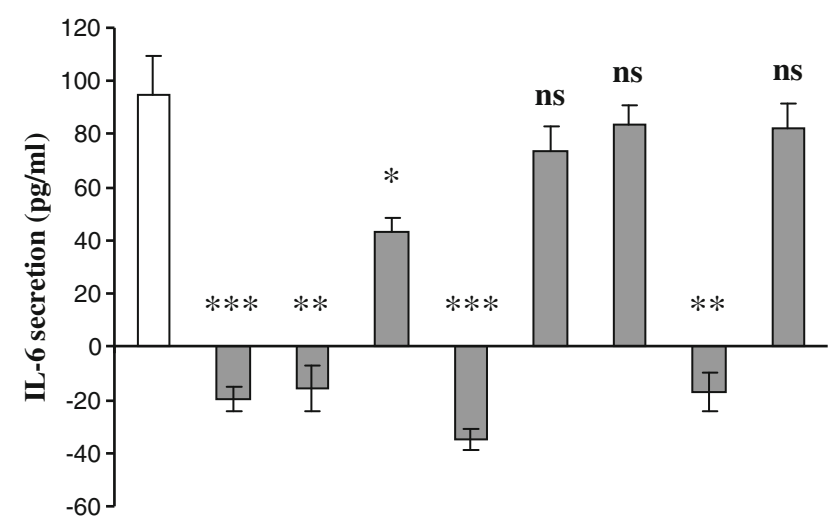

Fig. 4 GDPs modulate the inflammatory response. Human neutrophils were infected with $E$. coli for $3 \mathrm{~h}$ in the presence of GDPs; $3-D G$ $(307 \mu \mathrm{M}), 3,4-\mathrm{DGE}(48 \mu \mathrm{M}), 5-\mathrm{HMF}(16 \mu \mathrm{M})$ and formaldehyde $(12$ $\mu \mathrm{M})$, or in the presence of infusion fluids 2 and 3 with their respective controls (sf). E. coli-infected neutrophils were used as a positive control. Uninfected cells were used as a negative control. The presence of GDPs clearly suppressed secretion of both IL-6 and CXCL8 (see Supplementary Fig. 3). The results are means from six different blood donors. The statistical difference between GDP-treated neutrophils and the positive control was calculated with MannWhitney test/Student $t$ test $(* P<0.05, * * P<0.01, * * * P<0.001)$

bind to proteins immediately after infusion and their unbound concentrations were thus below the detection limit [12]. Therefore, none of the infused 3,4-DGE was detected in serum or in urine at the end of the study. Of the infused 3-DG in the glucose-containing infusion fluids, we found $2 \%$ unbound in serum and only $9.6 \%$ in urine at the end of our study. This means that $88 \%$ of the infused 3-DG is gone, possibly bound to serum proteins, giving rise to advanced glycation end products (AGEs) [13]. The serum amount of 5-HMF doubled during the experiment, and urinary secretion of this inert molecule increased fourfold. One explanation for the increased 5-HMF concentration might be that 3-DG is converted to 5-HMF through equilibrium with the reactive 3,4-DGE [17, 18]. This could explain the increased concentration of 5-HMF found in urine, but it also demonstrates that 3-DG is a reservoir for newly formed highly reactive 3,4-DGE.

There was a linear correlation between the amount of infused 3-DG and the increased formation of CML, a marker of AGE formation. Serum CML levels were low in the control patients receiving buffered saline in this study. The results are in good agreement with a recent publication by Humpert et al. [27] showing that human serum albumin (HSA) preparations for intravenous use contain high levels of CML. Furthermore, they found that the infusion of these CML-containing HSA preparations induced inflammation and caused increased mortality in experimental peritonitis. Furthermore, patients with renal failure accumulate 3-DG in serum due to impaired glucose metabolism and impaired renal clearance. In two recent studies, hemodialysis (HD) was shown to effectively remove AGEs and 3-DG, while an increase of this molecule was observed after PD treatment 
$[28,29]$. This discrepancy was found to originate from the fluids used in the two modes of dialysis, i.e., PD fluids contain high amounts of GDPs while the HD fluids were low in GDPs. Levels of AGEs are also known to be significantly elevated in postoperative complications after major operations such as surgical coronary artery revascularization and renal transplantation $[30,31]$. The patients in our study went through a broad range of fairly uncomplicated operations, but we found a restricted dissemination in serum CML concentration. This indicates that the increase is related to the infusion fluids rather than to the surgery.

Infusion fluids containing high levels of GDPs may have systemic effects resulting from local cytotoxic activity on blood vessels and blood cells, but also an indirect effect due to enhanced systemic AGE formation. Increased 3-DG has been shown to lead to a threefold increase in kidney lesions after 3 days in a rat model [32]. Among the patients in our study, we observed an eightfold increase in serum 3-DG after receiving 1.71 of GDP-containing infusion fluid. In more critically ill patients, it is not unusual for patients to receive 41 of infusion fluids every day, for 2 days or longer. The more reactive GDP, formaldehyde, is connected to various forms of cancer in humans [33], and Zwart et al. [34] showed that rats exposed to $10 \mu \mathrm{M}$ formaldehyde experienced a significant increase of cell turnover. However, the best way to state the possible importance of GDPs in clinical practice is perhaps to demonstrate what happens when they are blocked. It is well known that reactive carbonyl compounds play an important role in the development of diabetic complications. A promising drug candidate for treatment of diabetic nephropathy is pyroxidamine, which is currently on the Food and Drug Administration (FDA) "fast track" for phase III clinical trials [35]. Pyroxidamine is a scavenger for reactive carbonyl compounds such as 3-DG [36], and has been shown in a phase II clinical study to ameliorate nephropathy $[37,38]$, enhance whole-body insulin sensitivity [39], increase creatinine clearance, and reduce inflammation and formation of AGEs. These data suggest that sterilization improvement leading to GDP removal from infusion fluids could be beneficial for insulin sensitivity and renal protection in intensive care patients.
Severely hyperglycemic patients typically suffer from complications such as infections and decreased wound healing. Recent studies have revealed that GDPs interfere with carbohydrate metabolism [40]. In this study, we found that the most reactive GDP, 3,4-DGE, was present at concentrations that could decrease neutrophil viability and affect cell function. Furthermore, neutrophil exposure to GDPs or the infusion fluids significantly inhibited secretion of cytokines involved in inflammatory conditions. These findings show that normal postoperative fluid treatment involves infusion of potentially dangerous fluids into patients. These observations are in good agreement with a study by Catalan et al. [11] showing that GDPs cause neutrophil apoptosis. We analyzed the oxidative burst in human neutrophils treated with GDPs or infusion fluids as a functional measurement of neutrophil function upon bacterial infection. We found that the oxidative burst was greatly inhibited both by GDPs and by the diluted infusion fluids. The ability of GDPs to impair microbial killing could thus contribute to the infection susceptibility and decreased wound healing that are observed in hyperglycemic patients.

The results of this study indicate that normal postoperative fluid treatment involves infusion of dangerously high concentrations of GDPs. New manufacturing techniques have reduced the amounts of GDPs in medical fluids, making these more biocompatible [17, 18]. It seems evident that the same approach in manufacturing should be introduced for fluids for intravenous use.

Acknowledgments Supported, in part, by a Research Scientist Grant from the Swedish Medical Research Council (2005-7364 and 2008-5135). The employees of Gambro Lundia AB listed as authors participated with other authors in the study design, but did not participate in the collection, analysis, or interpretation of the data. The authors have not disclosed any potential conflicts of interest. We thank Dr. H. Janson for scientific support and Robert George Dewsnap for linguistic revision. We thank also Mrs. E. Svensson and Mrs. G. Forsbäck for excellent technical assistance and Mrs. A. Johansson for help with clinical material.

Open Access This article is distributed under the terms of the Creative Commons Attribution Noncommercial License which permits any noncommercial use, distribution, and reproduction in any medium, provided the original author(s) and source are credited.

\section{References}

1. Iapichino G, Albicini M, Umbrello M, Sacconi F, Fermo I, Pavlovich R, Paroni R, Bellani G, Mistraletti G, Cugno M, Pesenti A, Gattinoni L (2008) Tight glycemic control does not affect asymmetric-dimethylarginine in septic patients. Intensive Care Med $34: 1843-1850$
2. Michalia M, Kompoti M, Koutsikou A, Paridou A, Giannopoulou P, TrikkaGraphakos E, Clouva-Molyvdas P (2009) Diabetes mellitus is an independent risk factor for ICUacquired bloodstream infections. Intensive Care Med 35:448-454
3. Preiser JC, Devos P, Ruiz-Santana S, Melot C, Annane D, Groeneveld J, Iapichino G, Leverve X, Nitenberg G, Singer P, Wernerman J, Joannidis M, Stecher A, Chiolero R (2009) A prospective randomised multi-centre controlled trial on tight glucose control by intensive insulin therapy in adult intensive care units: the Glucontrol study. Intensive Care Med 35:1738-1748 
4. Finfer S, Chittock DR, Su SY, Blair D, Foster D, Dhingra V, Bellomo R, Cook D, Dodek P, Henderson WR, Hebert PC, Heritier S, Heyland DK, McArthur C, McDonald E, Mitchell I, Myburgh JA, Norton R, Potter J, Robinson BG, Ronco JJ (2009) Intensive versus conventional glucose control in critically ill patients. N Engl J Med 360:1283-1297

5. Wieslander AP, Nordin MK, Kjellstrand PT, Boberg UC (1991) Toxicity of peritoneal dialysis fluids on cultured fibroblasts, L-929. Kidney Int 40:77-79

6. Linden T, Forsback G, Deppisch R, Henle T, Wieslander A (1998) 3Deoxyglucosone, a promoter of advanced glycation end products in fluids for peritoneal dialysis. Perit Dial Int 18:290-293

7. Linden T, Cohen A, Deppisch R, Kjellstrand P, Wieslander A (2002) 3, 4-Dideoxyglucosone-3-ene (3, 4-DGE): a cytotoxic glucose degradation product in fluids for peritoneal dialysis. Kidney Int 62:697-703

8. Conaway CC, Whysner J, Verna LK, Williams GM (1996) Formaldehyde mechanistic data and risk assessment: endogenous protection from DNA adduct formation. Pharmacol Ther 71:29-55

9. Morgan LW, Wieslander A, Davies M, Horiuchi T, Ohta Y, Beavis MJ, Craig KJ, Williams JD, Topley N (2003) Glucose degradation products (GDP) retard remesothelialization independently of D-glucose concentration. Kidney Int 64:18541866

10. Justo P, Sanz AB, Egido J, Ortiz A (2005) 3, 4-Dideoxyglucosone-3-ene induces apoptosis in renal tubular epithelial cells. Diabetes 54:2424-2429

11. Catalan MP, Santamaria B, Reyero A, Ortiz A, Egido J, Ortiz A (2005) 3, 4-dideoxyglucosone-3-ene promotes leukocyte apoptosis. Kidney Int 68:1303-1311

12. Erixon M, Wieslander A, Linden T, Carlsson O, Jönsson JA, Simonsen O, Kjellstrand P (2007) 3, 4-DGE in peritoneal dialysis fluids cannot be found in plasma after infusion into the peritoneal cavity. Perit Dial Int 28:277278

13. Zeier M, Schwenger V, Deppisch R, Haug U, Weigel K, Bahner U, Wanner C, Schneider H, Henle T, Ritz E (2003) Glucose degradation products in PD fluids: do they disappear from the peritoneal cavity and enter the systemic circulation? Kidney Int 63:298-305
14. Sarafidis PA, Whaley-Connell A, Sowers JR, Bakris GL (2006) Cardiometabolic syndrome and chronic kidney disease: what is the link? J Cardiometab Syndr 1:58-65

15. Lin CL, Wang FS, Kuo YR, Huang YT, Huang HC, Sun YC, Kuo YH (2006) Ras modulation of superoxide activates ERK-dependent fibronectin expression in diabetes-induced renal injuries. Kidney Int 69:1593-1600

16. Garcia-Lopez E, Carrero JJ, Suliman ME, Lindholm B, Stenvinkel P (2007) Risk factors for cardiovascular disease in patients undergoing peritoneal dialysis. Perit Dial Int 27 suppl 2:S205209

17. Erixon M, Wieslander A, Linden T, Carlsson O, Forsback G, Svensson E, Jonsson JA, Kjellstrand P (2005) Take care in how you store your PD fluids: actual temperature determines the balance between reactive and nonreactive GDPs. Perit Dial Int 25:583590

18. Erixon M, Wieslander A, Linden T, Carlsson O, Forsback G, Svensson E, Jonsson JA, Kjellstrand P (2006) How to avoid glucose degradation products in peritoneal dialysis fluids. Perit Dial Int 26:490-497

19. Williams JD, Topley N, Craig KJ, Mackenzie RK, Pischetsrieder M, Lage C, Passlick-Deetjen J (2004) The EuroBalance trial: the effect of a new biocompatible peritoneal dialysis fluid (balance) on the peritoneal membrane. Kidney Int 66:408-418

20. Schmitt CP, von Heyl D, Rieger S, Arbeiter K, Bonzel KE, Fischbach M, Misselwitz J, Pieper AK, Schaefer F (2007) Reduced systemic advanced glycation end products in children receiving peritoneal dialysis with low glucose degradation product content. Nephrol Dial Transplant 22:2038-2044

21. Rippe B, Simonsen O, Heimburger O, Christensson A, Haraldsson B, Stelin G, Weiss L, Nielsen FD, Bro S, Friedberg M, Wieslander A (2001) Long-term clinical effects of a peritoneal dialysis fluid with less glucose degradation products. Kidney Int 59:348-357

22. Montenegro J, Saracho R, Gallardo I, Martinez I, Munoz R, Quintanilla N (2007) Use of pure bicarbonatebuffered peritoneal dialysis fluid reduces the incidence of CAPD peritonitis. Nephrol Dial Transplant 22:1703-1708

23. Lee HY, Choi HY, Park HC, Seo BJ, Do JY, Yun SR, Song HY, Kim YH, Kim YL, Kim DJ, Kim YS, Kim MJ, Shin SK (2006) Changing prescribing practice in CAPD patients in Korea: increased utilization of low GDP solutions improves patient outcome. Nephrol Dial Transplant 21:2893-2899
24. Wieslander AP, Andren AH, NilssonThorell C, Muscalu N, Kjellstrand PT, Rippe B (1995) Are aldehydes in heatsterilized peritoneal dialysis fluids toxic in vitro? Perit Dial Int 15:348-352

25. Ulbricht RJ, Northup SJ, Thomas JA (1984) A review of 5hydroxymethylfurfural (HMF) in parenteral solutions. Fundam Appl Toxicol 4:843-853

26. Kusunoki H, Miyata S, Ohara T, Liu BF, Uriuhara A, Kojima H, Suzuki K, Miyazaki H, Yamashita Y, Inaba K, Kasuga M (2003) Relation between serum 3-deoxyglucosone and development of diabetic microangiopathy. Diabetes Care 26:1889-1894

27. Humpert PM, Lukic IK, Thorpe SR, Hofer S, Awad EM, Andrassy M, Deemer EK, Kasper M, Schleicher E, Schwaninger M, Weigand MA, Nawroth PP, Bierhaus A (2009) AGEmodified albumin containing infusion solutions boosts septicaemia and inflammation in experimental peritonitis. J Leukoc Biol 86:589-597

28. Agalou S, Ahmed N, Thornalley PJ, Dawnay A (2005) Advanced glycation end product free adducts are cleared by dialysis. Ann NY Acad Sci 1043:734739

29. Agalou S, Ahmed N, Babaei-Jadidi R, Dawnay A, Thornalley PJ (2005) Profound mishandling of protein glycation degradation products in uremia and dialysis. J Am Soc Nephrol 16:1471-1485

30. Simm A, Wagner J, Gursinsky T, Nass N, Friedrich I, Schinzel R, Czeslik E, Silber RE, Scheubel RJ (2007) Advanced glycation endproducts: a biomarker for age as an outcome predictor after cardiac surgery? Exp Gerontol 42:668-675

31. Franke S, Muller A, Sommer M, Busch M, Kientsch-Engel R, Stein G (2003) Serum levels of total homocysteine, homocysteine metabolites and of advanced glycation end-products (AGEs) in patients after renal transplantation. Clin Nephrol 59:88-97

32. Brown TR, Su B, Brown KA, Schwartz MA, Tobia AM, Kappler F (2003) Modulation of in vivo 3deoxyglucosone levels. Biochem Soc Trans 31:1433-1437

33. Costa S, Coelho P, Costa C, Silva S, Mayan O, Santos LS, Gaspar J, Teixeira JP (2008) Genotoxic damage in pathology anatomy laboratory workers exposed to formaldehyde. Toxicology 252:40-48 
34. Zwart A, Woutersen RA, Wilmer JW, Spit BJ, Feron VJ (1988) Cytotoxic and adaptive effects in rat nasal epithelium after 3-day and 13-week exposure to low concentrations of formaldehyde vapour. Toxicology 51:87-99

35. Williams ME (2006) New potential agents in treating diabetic kidney disease: the fourth act. Drugs 66:22872298

36. Chetyrkin SV, Zhang W, Hudson BG, Serianni AS, Voziyan PA (2008) Pyridoxamine protects proteins from functional damage by

3-deoxyglucosone: mechanism of action of pyridoxamine. Biochemistry 47:997-1006
37. Nakamura S, Li H, Adijiang A, Pischetsrieder M, Niwa T (2007) Pyridoxal phosphate prevents progression of diabetic nephropathy. Nephrol Dial Transplant 22:2165-2174

38. Alderson NL, Chachich ME, Youssef NN, Beattie RJ, Nachtigal M, Thorpe SR, Baynes JW (2003) The AGE inhibitor pyridoxamine inhibits lipemia and development of renal and vascular disease in Zucker obese rats. Kidney Int 63:2123-2133
39. Muellenbach EA, Diehl CJ, Teachey MK, Lindborg KA, Archuleta TL, Harrell NB, Andersen G, Somoza V, Hasselwander O, Matuschek M, Henriksen EJ (2008) Interactions of the advanced glycation end product inhibitor pyridoxamine and the antioxidant alpha-lipoic acid on insulin resistance in the obese Zucker rat. Metabolism 57:1465-1472

40. Berstein LM, Vasilyev DA, Poroshina TE, Kovalenko IG (2006) Glucoseinduced effects and joker function of glucose: endocrine or genotoxic prevalence? Horm Metab Res 38:650655 